\title{
Welcome to Arrhythmia Grand Rounds
}

\author{
Ranjan K. Thakur, MD', Andrea Natale, MD² \\ 1 Sparrow Thoracic and Cardiovascular Institute, Lansing, Michigan, USA \\ 2 St. David's Medical Center, Texas Cardiac Arrhythmia Institute, Austin, Texas, USA
}

On behalf of Science International and Dr. Steven Korn, publisher, Betsy Bogdansky, Managing Editor and the editorial board, we welcome readers to the first issue of Arrhythmia Grand Rounds (AGR).

Initially, cardiac electrophysiologic investigations and treatments were only available to patients in advanced economies, but in the last one to two decades, very sophisticated levels of electrophysiologic interventions have become widely available all over the world. This means that sophisticated electrophysiologists are practicing all over the world and they have ongoing educational needs. Many traditional journals are not easily available to readers in parts of the world, largely because of cost. Fortunately, advancements in electronic media make it possible for people all over the world to meet virtually and learn together.

Arrhythmia Grand Rounds was envisioned several years ago as a premier educational venue for clinical electrophysiologists all over the world. It has taken some time to get to the first issue and we are delighted to welcome the readership. We hope to make the journal an ideal teaching and learning environment. We hope to make this process interactive, multimedia and democratic. This evolution will take some time and we encourage your participation and feedback to help us achieve these goals.

We have excellent traditional journals for dissemination of new research findings. However, clinicians enhance their clinical problem solving skills by dissecting and discussing difficult clinical cases with their colleagues and debating therapeutic alternatives - that's what this journal will aim to do. This journal will provide a case-based approach to clinical cardiac electrophysiology and in due course, we hope to become the preferred destination for unique case reports as well as case reports that offer teachable points. In addition, reviews, editorials, review questions, challenging ECGs, EGMs, and images, etc. from the global electrophysiologic community as well as thought leaders will enhance $A G R$ 's educational mission - to teach electrophysiology, one case at a time. We hope that all those who deal with arrhythmias - electrophysiologists, cardiologist, fellows in training, associated professionals and primary care physicians - will find the journal useful in furthering their knowledge. AGR has one very unique feature to enhance that mission. Case reports and other published material will also be available in slide format so that readers may easily download them and use them for teaching fellows, residents, colleagues and others.

All case reports, editorials, etc. in this journal will be peer reviewed and indexed using the d.o.i. indexing system . For contributors of peer reviewed contents, this will represent a peer reviewed publication. In due course, we will strive for Medline indexing.

The journal has assembled a veritable editorial board. Over the last several months, Dr. Paul A. Levine led the journal and made the first issue possible. Unfortunately, because of his sudden illness, he has asked us to take over as Co-Editors-in-Chief. We offer our best wishes and prayers to Paul and his family as 
they negotiate the difficult days ahead and hope for his full recovery. Dr. Levine will continue to actively participate in helping us shape and guide the journal. The torch has been passed to us and we will endeavor to fulfill the original vision. We shall appreciate your thoughts as to your educational needs and how we should meet those needs.

We thank our colleagues who have guided us in developing and encouraging this journal; they are too numerous to name individually, but we recognize their contributions and appreciate their encouragement. On behalf of the students and teachers of electrophysiology worldwide, we thank our friends in industry who support this educational endeavor. Education makes all of us better!

Again, on behalf of all of us, welcome to Arrhythmia Grand Rounds.

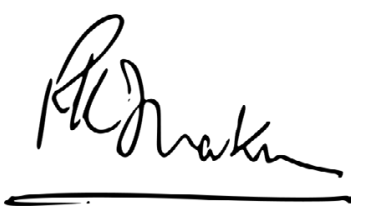

Ranjan K. Thakur, MD

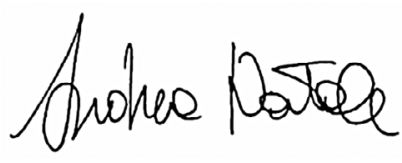

Andrea Natale, MD

Co-Editors-in-Chief

Arrhythmia Grand Rounds

\section{Comment on this Article or Ask a Question}

